\title{
Currency forecasting: an investigation of extrapolative judgement
}

\author{
Mary E. Wilkie-Thomson ${ }^{\text {it* }}$, Dilek Önkal-Atay ${ }^{h}$. Andrew C. Pollock"

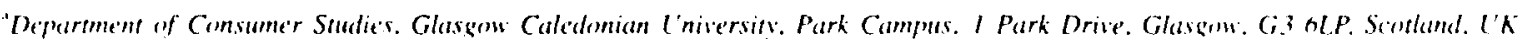 \\ "Facults of Business Administration. Bilkent L'niversity. (k,5:3 Bilkent. Ankara. Turke's

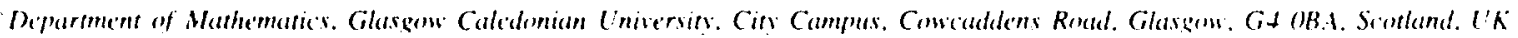

Received 20 suly 1006: received in revised form 28 February 1407: accepted 31 Maly 1097

\begin{abstract}
Nhstract
This paper aims to explure the potential effects of trend type. moise and forecast horison an experts and movices" probabilistic forecasts, The subjects mide forecasts ower six time horizons from simulated monthly cutrency series hased on

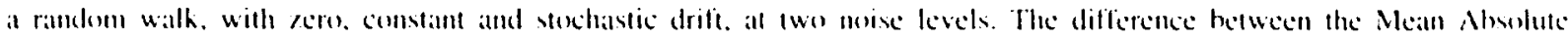
Probathility Score of cach participant and an AR(1) moded was uned to evaluate performance. The resulds thowed that the

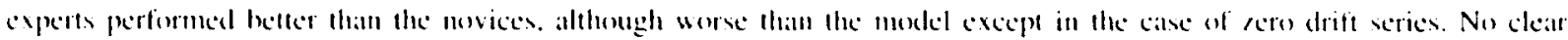

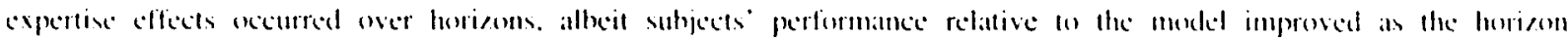

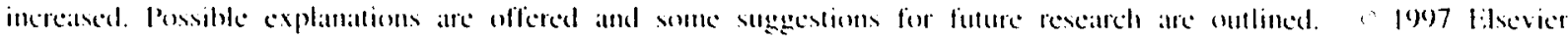
Sicince $13 . Y$.
\end{abstract}

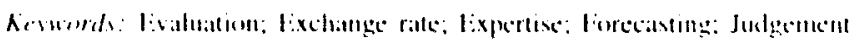

\section{Introduction}

Forecasts based on human judgement are widely used in pratcicial situattions (e.g. Dalrymple. 1987; Klein and Linneman. 1984). One such situation is currency forceisting. where predictions are oflen batsed on judgement alone or. alt the very least. in combination with stitistical models. This is especially the calse with the chartist forecasting approatch. which essentially consists of two principal judgemental tasks (Murphy. 1986). The tirst of these tasks is 10 identify trends at the beginning of their

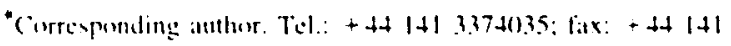
$3.37+420$.
}

development for the purpose of trading in the appropriate direction. The second task involves recognising when the price series is indicative of at trend reversal and distinguishing this situation from instances when apparent contradictory movements may only reflect noise. Despite the practical signiticance of judgement in this area, aceademic research has cended to be quantitatisely based. focusing on the advantages of one statistical forecasting method relative to another. Consequently. very little is known about the quality of professional currency forecasting judgement and how it is aflected by relevant characteristics such as the type of trend, the level of noise and the length of the forecalst horizon. This paper reports an exploralory investigation of these issues within a probability forecasting framework. 
Our focus on probabilistic forecasts stems from their advantages over point forecasts in presenting quantitative descriptions of forecaster"s uncertainty. hence. enabling their users to make more informed decisions (Murphy and Winkler. 1974. 1992). Comparative advantages of using judgemental probability forecasts have been emphasised in a variety of decision-making contexts (Wright et al., 1996). including financial domains. In a study carried out by Kabus (1976). seven top banking executives predicted the value of interest rates 3 months into the future and attached probability assessments to their predictions. These experts performed very well at predicting actual values, and the correct direction of movement wals predicted in all cases. In contrast. much of the carlier work examining prohabilistic forecalsting of stock prices has reported poor results. For instance. Stace bon Holstein (1972) compared stock price predictions of live subject groups - stock market experts, hankers, universily business keachers. business students and stattisticians. His subjects" predictions were astonishingly poor: only 3 out of 72 subjects performed better thatn a "uniform foreciaster" (i.c. a forecaster who assigns ecgual probabilitics to all possible occurrences). lurthermore, the relationship between level of expertise and accuralcy wals almost the opposite of what one would expect. The statisticians performed best, followed by the stock market experts, studemts, tealeders, and tintally billhers. This "inverted expertise" effect hats also been illustrated in two recent stock market studies. Yatles (t) al. (1991), in a study concerning both pricess and calrnings, found that the probabilistic foreciasts of 'movices' (i.e. undergraduatle business administration students) were more atceurate than that of semiexperts" (i.e. gratduate business students). Önkall and Wuradoglu (J9) a) analysed stock price forecasts. and found that students who had previously made stock investment decisions (i.e. semi-experts) performed worse than students with no active trading experience. However, both studles used students als "semi-experts" in concluding the effects of expertise. Also. Stacl von Holstein (1972): Yalles et al. (1991). and (Onkal and Muradeglu (199+) halve all employed multiple-interval task structures (where the forecaster is asked to report his/her predictions by assigning probabilities to a given number of intervals) as opposed to dichotomous task structures (where the forecaster predicts which of the two possible outcomes will occur and then assigns a probability for the chosen outcome's occurrencel. It is shown that the choice of task structure can have important implications for reporting and evaluating probability judgements (Ronis and Yates. 1987). Thus. the exclusive use of multiple-interval task format may be viewed as another important factor that should be considered in interpreting previous findings.

Focusing on the potential limitations of past research. Muradoglu and Önkal (1994) and Önkial and Muradoglu (1996) have investigated probabilistic forecasting performance of professional portfolio mamagers (i.e. experts) and other banking professionals participating in a portfolio mantagement workshop (i.e. semi-experts). Results suggested that forecisting horizon and task format were significant determiniunts of forecasting performance. As governed by these two fictors, the ecologicial validtity of the forecasting task (i.c. its agreement with experts natural enviromments) wals found to be of critical importance in explaining experts" performance. This conclusion supports Bulger and Wright (1994) contention that ecologicall validity and learnathility of tasks provide the critical valriables for understanding the contradictory lindings of expertise research. Accordingly, the alleged inverse-expertise effect of carlier studies was not found when performances of professional portfolio managers and other banking professionals were analysed (Ö)nal and Muradoglu. 1996). This research accentuated the need for further investigation to delineale the different dimensions of forecasting accuracy that caln be expected at various levels of expertise. One objective of the present study was to examine this issue within a currency forecalsting context, particularly in relation to important price series characteristics such as the types of trend and levels of noise. In order to proceed within this framework. we next review the literature specifically concerned with time series forecasting.

Many recent studies have focused on 'abstract' time series forecasting tasks. i.c. forecalsting under conditions where no information on the nature of the scries is provided to subjects (Goodwin and Wright. 1991; Webby and $0^{\circ}$ Connor. 1996). Although the abstract design is highly representative of the chartist 
forecasting approach outlined initially.' this is not the case in other decision making domains where contextual information is utilised in addition to time series information in the forecasting process. However. even in the latter cases, the design is still valid. As $\mathrm{O}^{\circ}$ Connor and Lawrence $(1989)$ have pointed out. the quality of time series extrapolative judgement cannot be directly examined unless other data (i.e. environmental cues) are eliminated. If environmental cues are not controlled. the subject is able to retrieve relevant information from memory and this is likely to result in judgement based on both time series and non-time series information. As such, little can be said about the possible causes of either good or bad performance: it is impossible to determine whether poor judgement, for instance. is the result of salient non-time series information (Tversky and Kathoman, 1973) or factors specitic to the series (e.g. Bolger and Harvey, 1993).

Abstract forecasting lasks have so far enabled various important issues to be addressed. Of particular relevance to the present investigation are studies which have examined subjects" ability (I) extrapolate from trended and random series. A pervasive tinding that has emerged from previous research is the tendency to under-estimate the strength of the trend (Andreassen. 1988: Liggleton. 1982: 1.awrence and Makridakis. 1989). This underestimation bias has been found to be particularly strong when subjects extrapolate from deterministic exponential functions (Wagenaar and Sigarial, 1975; Wagenaar and Timmers, 1978, 1979).

The ability to recognise randomness or to detect a trend from noisy datta are further issues that are of paramount importance to a currency analyst. Strong negative statements have been made in the psychological literature about the human concept of ramdomness. However, this view is arguably unjustified. For example, in a critique of this literature. Ayton et

\footnotetext{
${ }^{1}$ Chartists do not use contextual information dac to the belicel that all indicators of change ti.c. economic, political, psychologicall or otherwise) are reflected in the pallern of the price scrics itsell and. therefore, a study of price action is all that is nected (1) furcestst luture price movements (Murphy. 1986). The chartist is aware that there are caluses for tives and falls in currency rates. However, he or she simply desent think that the forceasting task requires a knowledge of these caluses.
}

al. (1989) have shown that many of the randomness tasks presented to subjects are logically and methodologically problematic. Wagenaar (1972) claims that studies have shown people to be poor at recognising randomness. but fails to cite any examples. In fact. very few studies have focused on recognition. and those that did exhibited good performance (e.g. Baddeley, 1966; Cook. 1967). Further support that there is a performance difference between recognition and production tasks comes from a time series study carried out by Harvey (1988). In this study. individuals were able to acquire internal representations of the process used to generate data points. but did not use these representations in a forecasting task.

Other studies have shown that people are able to detect a known trend from noisy data. For example. Mosteller et al. (1981) and Lalwrence and Makridakis (1989) found that the level of noise did not affect the ability to identify a trend. However, this was not the calse in a study by Andreassen and Kraus (199()) which found that subjects tended to identily a trend more often when the signal was strong relative to the noise level.

Studies of extrapolating. rather than detecting. trends from noisy data have atso produced contradicfory lindings. Much of this research has compared humatn judgement to statistical models. Some studies have found humatn judgement to be less alceurate than quantitative methods. For instance. Adam and libert (1976) conducted a comparison study to ansess the impact of pattern complexity (comprising trend. trend with low and high seasonally) and the degree of noise and found these factors to have a significant detrimental eflect on performance. However, it has been asserted that when the underlying signal of a series is unstable, human judgement can outpertorm. or at least rival. statistical models. For instance, Latwrence (1983) compared judgement with statistical torecasts obtained via exponential smoothing and Box-Jenkins lechniques on a series of US airline passenger data and found little difference in accuratcy. Similarly. Sanders and Ritzman (1992) found good judgemental performance relative to statistical models with higher variability series. However, it appears that people perform poorly relative to statistical models when extrapolating more complex 
stable signals from noisy data. For instance. for a high noise step function. Sanders (1992) found human judgement to perform much worse than a statistical method. In a similar vein. Remus et al. (1995) documented the forecasters overreaction to immediate past information. implicating the problems that may be confronted in assessing randomness.

A number of studies have focused on the effect of length of the forecast horizon on judgemental accuracy. There is evidence relitting to both novices and experts that an inverse relationship exists between accuracy and the length of the forecast horizon. Lawrence and O'Connor (1992), with non-experienced subjects. and Basi et al. (1976), with professional security analysts, found accuracy to be greater in the shorter horizons. A reason for this may be found in the Bolger and Harvey (1993) study. They suggested that subjects tended to make repetitions of previous forceasts as the horizon length increases fat form of anchoring and adjustment heoristic with adjustment set ats gero). With the presence of at trend, this heuristic would result in a decrease in accuracy as the horizon is lengthened. However, in one of the few studies relating to currency forceasting. we (Wilkic and Pollock, 1994) found that professional forecasters performed worse in the short term. In this study. the professionals were compared to mathematicianss (with no experience of currencies) and interesting horizon effects emerged aldhough overall pertormance wats similar. Overall, the study suggested that professionals and non-professionals are likely to be influenced differently by specific characteristics of the foreciasting tilsk.

In view of the literature cited above, this study is designed to explore lime series extrapolative judgement in a currency forecisting context. The goal is to investigate the potential effects of trend. noise. and forecalst horizon on judgemental probability forccasts based on abstract time series. The use of abstratet series aids our attempts to discern the comparative forecasting performance of experts and non-experts operating under identical historical information. Accordingly. Section 2 presents the simulatted data used in this study. and the methodology is given in Section 3. Section + provides the results. while
Section 5 presents conclusions and directions for further research.

\section{Characteristics of exchange rate series and the simulation of the data}

This section discusses the nature of exchange rate behaviour and the method by which the data used in the present study were obtained to exhibit the relevant characteristics. The principle feature of actual values of currency series is that they are not stationary: the variance and covariance depend on time even when logarithmic values are used. In particular. the variance tends to increase over time and lirst order serial correlation with a value close to unity is likely to be present. Series of this form cinn. however. be made stationary by some simple transformations. Taking first differences of the actual logarithmic values simultaneously takes out the effect of a lincar trend in the series (i.e. giving comstant drift in the diflerence dittil) and the antocorrelation (i.c. a lirst order scrial correlation coefficient close to unity in the actuat datal has a value close to acro in the difference ditis). In oher words. currency series tend to follow what Nelson and Plosser (1982) describe as a difference stationary process (i.e. non-stationary arising from the accumulation over lime of stationary and inevitable tirst differencess) rather than a trend stationatry process (i.c. stationary fluctuations around a delerministic trend). In this difference stationary framework, the trend term in the actual series is alssociated with the drift term in the first differences. A constant drift gives rise to at linear trend and at variable drift gives rise 10 a non-linear trend. Zero drift implies that there is no trend.

The Eificient Markets Hypothesis (EMH) is often referred (1) als the random walk view and is supported by a number of studies (c.g. Crumby and Obstlield. 1984: Boothe and Glassman. 1987). This view implies that currency movements follow an identical and independent distribution over line. This randem walk process (for the actual logarichmic values) woukd tend to meander away from the starting value but exhibit no particular trend in doing so and is. therefore. dependent on its initial value and the 
cumulative effect of random error movements from the initial period. Movements in this type of series are purely random with zero drift. As this type of series provides a hasic starting point in examining currencies. it forms the basis of the tirst set of simulated series (i.e. Model 1) which is statistically detined below. The error term can be modelled as a normally distributed random variable.

The trend in the actual (logarithmic) series (drift in the logarithmic difference series) is the major characteristic in currency series that is of use to the forccaster when extrapolating from past and present values of the data. Both chartist and fundamental currency forecasting techniques are essentially designed to identily trends in financial series. The time series path of the spot exchange rate (as opposed to futures or lorward exchange rates) often exhibits a major trend te.s. an examination of the Swiss lis.t I $K$ f clearly shows a relative depreciatling $f$ over the last 20 years). Such a trend arises from lundamentals in the loneign exchange market, the most important of Which is Purchasing Power Parity (P'Pl') Pl'P tates that exchallege rates adjust on olliset dillerentials in relallice price shangen (i.ce inllation ralles) between commeries which call persist arer the lome lerm. Resulls from ()llicer (1952) and Polleck (1989)a), (1989)), (190()h) support the lomg run validity of Pl'l. If it is assumed that relative price movements

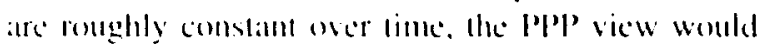
support the presence of approximately lincar trends III currency series: comslant driti. As commeries hate dilfering rates of interest fhigh inflation conturies ende fo have higher lates of inferest than low mbation countries). long term speculative gaims on the movement of the cumenty would tend to be atived by inlerest rate differentials stech thatl the erende can persist over time. An approximately linear frend in a fogarithmic currency scrices is consistent with this view, hemes it is appropriatle to comsider drilt an mom-ecro and comstame over lime. This ifproach provides the second group of simulated erries (i.e. Model 2). This mokel can have positive drift and megative drill and is consistent with the 1. Noll if interest rate differemeials fully explain the driti.

While major trends can persist over the long term. minor trends can oceur due to the time it takes information to be incorporated into exchange rates. Short term fundamentals can arise from asset market factors. These include: oil shocks arising from events such as the Irayi invasion of Kuwait: political unrest in the former LSSR: conflicts in the former Yugoslavia: and other political and economic changes or less spectacular events such as the resignation of a prime minister or an announcement of good trade figures. If intormation from such events is incorporated into the drift term over time, consecutive values will be influenced in the same direction caltsing the drift to show positive atutocorrelation. That is. there would be an initial effect and subseyueme effects that decrease over time, which is consistent with a short term variable drift pattern. This approalch comsiders that over several periods the exchange rate mowes in the same direction subject (1) random variation and other things being equal) towards a mean comstant drift rellecting the major tremb). If this mean is cero the model would sugegest that the exchatlec rate is inflenced by a series of events which form (by assumptiom) an itregulan paltertl. This pattern can be molelled by using a random error cerm that lollows a mormal distribution. Hence, the mokel comtains lwo corror terms, once that reflects pute random variation (ats in the canse of the random walk mosele and anowher which rellects the eflect of (tanderm) events on drift, the etfece of which decteases over time. This lype of series provides the third group of simulated series - variable driti with a aron mean (i.t. Model 3).

The assumplion made above of a kero mean caln be relaxed to allow positive or negative drift in the longer term resulting in a price trend model which allows major and minor trends in the currency seriss It is this type of series that provides the lourth type of simulated series (i.e. Mosel t) - variable drift with a positwe or negatte mean. This model exhibits both matjor and minor trends around random flactuations and call be justitied in the same way as the above molels. In this casce however, both comstant and stochastic driti oceur in the same model.

These four models. Herclore. tatke into alcount hoth long and short term (major and minor) trends in the exchange rale. Model I contaims no long term or short lerm influences. Model 2 considers only long 
term influences. Model 3 considers only shor term influences, and Model + considers both long term and short term influences. These four models can be simulated by defining the drift term as a linear and/or stochastic variable that follows a first order autoregressive (AR) process. Pollock (1990a) used various models of this form in the context of Italian Lira/UK $f$ exchange rate forecasting. In the examination of exchange rate behaviour. an AR(1) model for the drift term is an appropriate specification (Taylor, 1980, 1986). Taylor (1989) illustrates a method for constructing daily financial data. By choosing appropriate parameters. Taylor's procedure can be applied to monthly exchange rate data. The design of the simulated series (described above) was based on this price trend model with parameters chosen to reflect a random walk with: (i) zero drift Model 1; (ii) constant drift - Model 2; (iii) stochilstic drift - Model 3 and: (iv) constamt and stochastic drift - Model 4.

In modelling the noise component a natural choice is the normal distribution. We (Pollock and Wilkie. 1996; Pollock et al. 1996) have lound for weekly forecasts of the US $\$ / U K \mathcal{E}$ and JapancseYon/(ierman DM that the assumption of normally distributed first differences wass approprialte if allowante wass made for time varying paramelers. The case for the assumption of normality is evell stronger in the case of the longer horizon, monthly datia."

In order to examine the impact of noise on the judgemental identilication of the major and minor trends, high and low variance specifications for the four models delined above were included. No attempt was made to incorporate changing variances within particular scries: the identification of changing variances within a series is a difticult lask without statistical antysis. Each series, therefore, was given a constant variance.

The simulated currency series were obtained by using a modification of the Price Trend model of Taylor (1989). This model is set out in Eq. (1) and (2):

\footnotetext{
'The Central limit Theorem suggests that, as exchange rale changes between two points in time are essentially the sum of changes over shorter horizons. the distribution will tend to normality. even if the underlying distribution is not mormal, provided this underlying distribution is stable.
}

$\Delta y_{t}=T_{t}+\varepsilon_{t}$

$\left(T_{t}-\mu\right)=\rho\left(T_{t-1}-\mu\right)+\nu_{t}$

where: $\Delta$ is a first difference operator and $y$, is the logarithm of the exchange rate such that $\Delta_{y_{1}}=y_{t}-$ $y_{t-1}: T_{t}$ is the drift term; $\rho$ is the autocorrelation coefficient: $\mu$ is the mean of $\Delta_{y_{t}} ; \varepsilon_{t}$ and $\nu_{t}$ are independent and identically distributed normal random variables with expected values of zero and variances of $\sigma^{2}$ and $\sigma_{r}^{2}$, respectively; $A$ is defined as the signal to noise ratio $\sigma_{s}^{2} / \sigma_{c}^{2}$ : subscripts $t$ and $t-1$ denote time: variances are $V\left(T_{1}\right)=\sigma_{r}^{2} /\left(1-\rho^{2}\right)$ and $V\left(\Delta y_{1}\right)=\sigma_{j x}^{2}=\sigma_{\alpha}^{2}+\sigma_{1}^{2} /\left(1-\rho^{2}\right):$ and the initial values for $y$ and $T$ are set at $y_{0}=0$ and $T_{0}=\mu$.

To set the parameters $\left(\mu, \sigma_{r+\ldots} . A, \mu\right)$, the actual series of monthly cross rates between five major currencies (UK Pound. US Dollar, Japanese Yen. German DM and Swiss Franc) were obtained for the period December 1973 to December 1994. The figures for each series were indexed to a value of unity for December 197.3. Logarithmic values to base ten were then obtained so that the value for December 1993 became zero. The data were then first difference giving a scries for the period January 1974 (o) December 1994. The means, standard deviations and first order autocontelittion coefiticients were obtained for earch series (sce Table I for estimates). These estimates provided the guidelines on which the parameters of the models were detined.

Using the results in Table 1 ats a guide and taking into account the need for appropriate values that allow some degree of judgemental recognition in the series, the parameters chosen for the simulated series are detined ats in Table 2.

To compare an individual's judgemental predictions with the optimall, it was necessary to obtain theoretical expected point values for the $1-6$ month ahead foreciasts (i.e. for months 61-66). These are set out in Appendix $\mathrm{A}$.

\section{Methodology}

Participants of this study came from two groups. One group consisted of ten members of the FURO Working Group on Financial Modelling. This expert' group wals comprised of academics and prac- 
Table 1

Estimated parameters tor the price trend model

\begin{tabular}{|c|c|c|c|}
\hline \multirow{2}{*}{$\begin{array}{l}\text { Mujor cross exchange rates - tirst differences } \\
\text { Rute }\end{array}$} & \multicolumn{3}{|c|}{ January 1974 to December 1994} \\
\hline & Mean & S.D. & Autocorrelation coeff. \\
\hline US Dollar/LK Pound & -0.0007 & $0.01+7$ & 0.102 \\
\hline Japan Yen/UK Pound & -0.0025 & $0.01+3$ & 0.109 \\
\hline German DM/UK Pound & -0.0016 & 0.0118 & 0.107 \\
\hline Swiss Franc/UK Pound & -0.0023 & 0.0130 & 0.121 \\
\hline Japanese Yen/US Dollar & -0.0018 & 0.0145 & 0.025 \\
\hline German DM/UK Dollar & -0.0010 & 0.0148 & -0.002 \\
\hline Swiss Franc/UK Dollar & -0.0016 & 0.0164 & 0.042 \\
\hline Japanese Yen/German DM & $-0.0(x) 8$ & 0.0131 & 0.055 \\
\hline Swiss Franc/German DM & -0.0006 & 0.0070 & 0.169 \\
\hline Japancse Yen/Swiss Franc & -0.0002 & 0.0138 & 0.036 \\
\hline
\end{tabular}

Tiable 2

Parameler set for the simulated series

\begin{tabular}{|c|c|c|c|c|}
\hline \multirow[t]{2}{*}{ Mirlel } & \multicolumn{4}{|c|}{ Parameters } \\
\hline & $p$ & $\sigma_{n}, \ldots$ & $A$ & $\mu$ \\
\hline \multicolumn{5}{|l|}{ Ziro drift - Modell I } \\
\hline L.ow nowse & 0 & 0.01 & 0) & 0 \\
\hline High noise & 0 & 0.02 & ) & 0 \\
\hline \multicolumn{5}{|l|}{ Comstumu drift - Modelel : } \\
\hline l.uw moise, positive constant drift & 0 & 0.01 & 0 & 0.0012533 \\
\hline l.ow noisc, megallive comstant drift & 0 & 0.01 & 0 & $-0.0 \times 2533$ \\
\hline Iligh noisc: pesitive comstitnt dritt & () & 0.112 & () & $0.0 \times 1253.3$ \\
\hline High noisc. negattive constant drift & 0 & 0.02 & 0 & $-0.0 x) 25.33$ \\
\hline \multicolumn{5}{|l|}{ Sien Heastic drift - Model i } \\
\hline L.uw noise & 0.5 & 0.01 & 0.2 .5 & () \\
\hline High moise & 0.5 & 0.02 & 0.25 & 0 \\
\hline \multicolumn{5}{|c|}{ Constumt and stochastic drift - Mode't +} \\
\hline Luw moise, positive constant drilt & 0.5 & 0.01 & 0.25 & 0.002533 \\
\hline Low moisc, negative constant drift & 0.5 & 0.01 & 0.25 & $-0.0 \times 1) 2533$ \\
\hline High moise, positive constant drilt & 0.5 & 0.02 & 0.25 & 0.002533 \\
\hline High moise, negattive constant drift & 0.5 & 0.02 & 0.25 & -0.002533 \\
\hline
\end{tabular}

Note: For Models 3 and + the values of $p$ and $d$ of 0.5 and 0.25 respectively are consisfent with a first order atutexurrelation coefficient of 0.125 .

titioners from different European countries. All of these individuals had considerable expertise in financial forecasting including knowledge of the nature of currency series and sufficient understanding of judgemental probability forecasting. Finally. these individuals were proficient with chartist techniques.

The second group consisted of 30 third-year management students taking a forecasting course at Bilkent University. Turkey. This "novice" group was exposed to judgemental probability forecasting via their forecatsting course, and had limited domain knowledge via a previously-taken tinance course."

Simulated data for the time paths of 32 series were

'Students in the 'non-expert' group were exposed to random walk processes and liMH concepts at an elementary level. These subjects' comparatively limited domain knowledge and minimal experience induces their classification as 'novices'. On the other hand, professiomal qualilications of the inembers of the EURO Working Group on Financial Modelling substantiate their identilication as the "expert" group. 
presented graphically to the subjects. The subjects were not told anything about the nature of the data or that they were constructed. only that they reflected logarithmic values of currency series. The series were presented for a 60 month period (months were numbered from 1 to 60 ) and indexed with the initial value (for month 0 ) set at zero.

The subjects were asked to study each series and make directional forecasts over six horizons (i.e. for months 61 10 66). They were also required to indicate how certain they were about each prediction by assigning a probability (between $50 \%$ and $100 \%$ ). The subjects completed the task at their own pace and convenience.

A comparison of subjects predictions with expected probabilities were made using a range of probability accuracy meisures which essentially involved the calculation of the Mean Absolute Probability Score (MAPS) and the associated mealsures of the Mean Response $\{M(r)\}$ antel Bias $(B)$. These essentially follow the lines of the covariance decomposition approach. set oul in Yates (1982). (1985), but with moditications lo take into account the magnitude of movements in the series (sect Wilkie and Pollock, 1996). These alle oullined below.

Once the subjects" forecasts were obtained a weighted outcome index $(c)$ for ealch forcecist $i$ wals calculalted for each forecaster as detined in licp. (3):

$c_{1}=0.5+11$

To apply the proposed framework, it was necessaly to calculate the neight $\left(w_{,}\right)$in the weighted outcome index $(c$ ) for each forecist $i$. As defined in Wilkic and Pollock (1996), the quantity. 0.5, plus the absolute value of this weight (i.e. $0.5+|w|$,$) call be$ viewed as a probability that reflects the relative magnitude of a movement in the currency series all period $i$. The sign of $w^{\prime}$, reflects whether the lorecaster is correct $(+)$ or incorrect $(-)$. Since the series used in the present study were simulited, this weight was known with certainty as the signal and error terms could be identilied. In this calsc, $\{0.5+$ $\left.\left|w_{1}\right|\right\}$ wals the theoretical probability of the predicted change in the series at forecist $i$ (i.e. in the appropriale direction).

The subjects' performatnee wats compared with the hypothetical random walk forceister. The random walk forecaster assigns all probabilities as 0.5 with an arbitrary direction. An individual who views the currency market as efficient with exchange rate movements following a random pattern would make predictions in a similar way. The expected value of the weighted outcome index $\left\{i . e . M(c)=\Sigma c_{i} / n\right\}$ for the random walk forecaster is 0.5 .

The MAPS. which is closely related to the Mean Absolute Error (MAE). was computed using the modified outcome index. This is defined in Eq. (4):

$$
\text { MAPS }=\sum\left|r_{1}-c_{i}\right| / n
$$

where $r_{i}$ is the probability response for forecast $i$. The MAPS has an expected value for the random walk forecister of $\Sigma|p| / n$.

The MAPS represents a form of linear loss function (the penalty altached to the error is proportional to the size of the error) in contrast to the widely used Mean Probability Score (MPS) which lakes the form of a cuaddratic loss function (the perlalty attiched is propertional to the sequare of the error). It was considered more appropriatce to use MAPS in this study as it is likely that the subjects would have tended, inluitively, to view the consegucolless of the error in a linear way. It has heen printed out by keren (|90)|) that the loss function used in assessing probabilistic forecasting performince should be approximaltely consistent with the framework in which subjects make their predictions.

To stepplement the interpretition of MAPS, Iwo other alceraray measures were calculated. These measures were the Mean Response $\{M(r)\}$ and Bias $\{B=M(r)-M(c)\}$. Bials meatsures the degres of under/overeonfidence in predictions. It is positive in calses of overcontidence and negative in calses of under conlidence. The expected value of $B$ is $/$ ero for the random watk forecaster.

The MAPS and associated measures. however. vary across the types of series with different charalcteristics and random valriation with the result that interpreting a subject's performance between different situations becomes difficult. It was, therefore, appropriate to use a relative standard of comparison. In this study. the MAPS Dilference (MAPSD) wals used. which is defined als the difference between alch subject's MAPS (and $M(r)$ and $B$ ) and the MAPS fand $M(r)$ and $B$, respectively) obtained from 
applying a tirst order Autoregressive Model Order One $\{A R(1)\}$ to the first differences of the series. Each subject's performance was. theretore. measured relative to the model. which facilitated comparisons of experts and novices based on various series characteristics. While the MAPS can only take positive values with the hest possible measure attainable being zero, the MAPSD can take positive or negative values. A positive value would indicate that the subject's performance was worse than that of the $A R(1)$ model and a negative value would indicate that the subject's performance was better. To provide additional information the $M(r)$ Difference $\{M(r) D\}$ and Bias Difference (BD) were also considered. The AR(1) model was chosen because it has been used in a currency forecasting context (Pollock and Wilkie. 1992) and because it can be used of identify both the linear trend (comstant drift) and the low level of atutocorretation (at feature of stochastic drilt). Due to the statistical problems associated with the ielentilicaltion and separation of the two croror lerms $\left(s_{\text {, }}\right.$ and $\left.t_{f}^{\prime}\right)$. variable parameler techniques were not considered stitable for providing a more apperopriatc model.

\section{Results}

A Splie Plot (Mixed) ANOVA was applied to the dependent vartiable. MAPSis). with four independent fictors: (1) Expertixe (expert/movice): (2) Horizon (1-6 months): (3) Series Type (1. 2. 3 and + derived fom Models 1, 2, 3 and + respectively, i.e. zero. constint, stochanstic, and stochastic with constant drift): and (t) Noisc (low/high). Expertise was a hetween-subjects factor and Horizon. Series Type and Noise were within-subjects lactors. As the subjects were chosen from the members of the Euro Working (joup on Fintucial Modelling (in the (xperts cance) and management students at Bilkent University (in the novice cates) they were treatted als tixed factors. In addition. as there were 10 experts and 30 students, the ANOVA look the form of an unbalanced design. The four factor interation lerms were excluded from the analysis to provide the error term. To complement the results and provide additional intormation. the procedure was also repeated with Mean Response Difference $\{q(r) 1)\}$ and Bias Difference (BD) as dependent variables. Accuracy components such as the Weighted Outcome Index. Slope and Scatter could not be included as the zero drift model gives the same constant values in all cases. The mean values for the MAPSD. $\{M(r) D\}$ and (BD) for single factor effects and two way interaction with series type are set out in Table 3 Table 4 Table 5. Table 3 also gives respective values of the MAPSD for the random walk forecaster relative to the AR( 1 ) model.

Important single factor effects were highlighted by the analysis for the MAPSD. There was a significant expertise effect $\{F(1.585)=238.55, P<0.001\}$ which reflected that experts clearly performed better than novices, although performance in both cases was poorer than the AR(1) model (Table 3). This was probahly due to the experts giving a much lower mean response than the $A R(1)$ model while the novices gave similar levels of response to the model but exhibited a poorer directional probability performance (Table t). Hence, the experts" bials scores were similar to the model's, whereals the novices proved to be quite overcontident (Table 5). Hexpertise, therefore, did appear to improve performance There was also a signilicant horizon effect $\{f(5.585)=10.15, P<(0.0) 1\}$ which illustrated that, with the exception of the one month horizon, relative perlinmance over the model improved as the horizon lengeh increased (Tathle 3). The model, however, still performed beller than the subjects in all horizons and better than the random walk forecaster. One explanattion for this is that the subjects' mean response decreased relative of the model as the horizon increased, so that for horizons of 2 or more months, it was less than the $A R(1)$ model (Table 4). The result wats that the cleatr overconfidence relative to the model displayed for the 1-month horizon was signiticantly reduced to reveal slight under contidence for the 6-month horizon (Table 5). The subjects. therefore appeared less contident of a drift persisting inte the future than the model. The type of series also hald a major effect $\{F(5.585\}=1+16.90)$. $p \times() .(0) \mid\}$. The subjects performed similar to the random walk forecaster where the scries contained a constiant drift etement but their performance was worse than the $A R(1)$ model (Table 3). The subjects pertioned similarly to the $A R(1)$ model in the zero drift case, but this performance decreased with the presence of stochastic and constant drift. Perform- 
Table 3

MAPS differences - subjects and random walk forecaster

\begin{tabular}{|c|c|c|c|c|c|c|c|}
\hline & \multicolumn{4}{|c|}{ Series type/drift } & \multirow[t]{2}{*}{ All } & \multicolumn{2}{|l|}{ Noise } \\
\hline & $\begin{array}{l}\text { I } \\
\text { Zero }\end{array}$ & $\begin{array}{l}2 \\
\text { Constant }\end{array}$ & $\begin{array}{l}3 \\
\text { Stochustic }\end{array}$ & $\begin{array}{l}4 \\
\text { Stochatic } \\
\text { and constint }\end{array}$ & & Low & High \\
\hline \multicolumn{8}{|l|}{ Expertise } \\
\hline All & 0.002 & 0.062 & 0.029 & 0.136 & 0.057 & 0.056 & 0.059 \\
\hline Novice & 0.014 & 0.066 & 0.039 & 0.139 & 0.064 & 0.063 & 0.065 \\
\hline Expert & $\begin{array}{c}-0.032 \\
(-0.083)\end{array}$ & $\begin{array}{c}0.051 \\
(0.062)\end{array}$ & $\begin{array}{c}0.001 \\
(-0.027)\end{array}$ & $\begin{array}{c}0.127 \\
(0.135)\end{array}$ & $\begin{array}{c}0.037 \\
(0.022)\end{array}$ & $\begin{array}{c}0.034 \\
(0.012)\end{array}$ & $\begin{array}{c}0.039 \\
(0.031)\end{array}$ \\
\hline \multicolumn{8}{|l|}{ Horison } \\
\hline 1 month & $\begin{array}{c}0.048 \\
(-0.046)\end{array}$ & $\begin{array}{c}0.064 \\
(0.025)\end{array}$ & $\begin{array}{c}0.043 \\
(-0.019)\end{array}$ & $\begin{array}{c}0.103 \\
(0.061)\end{array}$ & $\begin{array}{c}0.065 \\
(0.005)\end{array}$ & $\begin{array}{c}0.078 \\
(0.019)\end{array}$ & $\begin{array}{c}0.052 \\
(-0.009)\end{array}$ \\
\hline 2 month & $\begin{array}{c}0.028 \\
(-0.063)\end{array}$ & $\begin{array}{c}0.060 \\
(0.0+5)\end{array}$ & $\begin{array}{c}0.037 \\
(-0.015)\end{array}$ & $\begin{array}{c}0.1+2 \\
(0.113)\end{array}$ & $\begin{array}{c}0.067 \\
(0.020)\end{array}$ & $\begin{array}{c}0.071 \\
(0.021)\end{array}$ & $\begin{array}{c}0.062 \\
(0.018)\end{array}$ \\
\hline 3 month & $\begin{array}{c}0.008 \\
(-0.080)\end{array}$ & $\begin{array}{c}0.063 \\
(0.059)\end{array}$ & $\begin{array}{c}0.036 \\
(-0.019)\end{array}$ & $\begin{array}{c}0.136 \\
(0.135)\end{array}$ & $\begin{array}{c}0.061 \\
(0.024)\end{array}$ & $\begin{array}{c}0.059 \\
(0.016)\end{array}$ & $\begin{array}{c}0.063 \\
(0.032)\end{array}$ \\
\hline 4 month & $\begin{array}{c}-0.013 \\
(-0.092)\end{array}$ & $\begin{array}{c}0.057 \\
(0.071)\end{array}$ & $\begin{array}{c}0.024 \\
(-0.028)\end{array}$ & $\begin{array}{c}0.146 \\
(0.154)\end{array}$ & $\begin{array}{c}0.054 \\
(0.026)\end{array}$ & $\begin{array}{c}0.049 \\
(0.010)\end{array}$ & $\begin{array}{c}0.058 \\
(0.042)\end{array}$ \\
\hline 5 month & $\begin{array}{c}-0.025 \\
(-0.103)\end{array}$ & $\begin{array}{c}0.062 \\
(0.082)\end{array}$ & $\begin{array}{c}0.021 \\
(-0.0 .37)\end{array}$ & $\begin{array}{c}0.141 \\
(0.167)\end{array}$ & $\begin{array}{c}0.050 \\
(0.027)\end{array}$ & $\begin{array}{c}0.041 \\
(0.005)\end{array}$ & $\begin{array}{c}0.058 \\
(0.049)\end{array}$ \\
\hline 6 month & $\begin{array}{c}-0.032 \\
(-0.113)\end{array}$ & $\begin{array}{c}0.0(x) \\
(0.0(1) 2)\end{array}$ & $\begin{array}{c}0.016 \\
(-0.04 .5)\end{array}$ & $\begin{array}{c}0.148 \\
(0.174)\end{array}$ & $\begin{array}{c}0 .(240) \\
(0.028)\end{array}$ & $\begin{array}{c}0.039 \\
(0.00) 1)\end{array}$ & $\begin{array}{c}0.060 \\
(0.056)\end{array}$ \\
\hline \multicolumn{8}{|l|}{ Noise } \\
\hline l.ow & $\begin{array}{c}-0.0 .38 \\
(-0.137)\end{array}$ & $\begin{array}{c}0.0 .34 \\
(0.02(0)\end{array}$ & $\begin{array}{c}0.078 \\
(0.022)\end{array}$ & $\begin{array}{c}0.1 .44 \\
(0.1+4)\end{array}$ & $\begin{array}{c}0.056 \\
(0.012)\end{array}$ & & \\
\hline Iligh & $\begin{array}{c}0.042 \\
(-0.029)\end{array}$ & $\begin{array}{c}0.084 \\
(0.1(4)\end{array}$ & $\begin{array}{c}-0.0119 \\
(-0.077)\end{array}$ & $\begin{array}{c}0.128 \\
(0.120)\end{array}$ & $\begin{array}{c}0.059) \\
(0.0311)\end{array}$ & & \\
\hline Ainertive/men & & & & & & & \\
\hline Novice/low & -0.024 & 0.046 & 0.085 & 0.147 & 0.06 .3 & & \\
\hline Lxpert/low & $\begin{array}{c}-0.080 \\
(-0.137)\end{array}$ & $\begin{array}{c}0.021 \\
(0.020)\end{array}$ & $\begin{array}{c}0.058 \\
(0.022)\end{array}$ & $\begin{array}{c}0.138 \\
(0.1+4)\end{array}$ & $\begin{array}{c}0.034 \\
(0.012)\end{array}$ & & \\
\hline Nuvice/high & 0.051 & 0.085 & -0.007 & 0.132 & 0.065 & & \\
\hline lixpert/high & $\begin{array}{c}0.016 \\
(-0.029)\end{array}$ & $\begin{array}{c}0.0 \times 2 \\
(0.105)\end{array}$ & $\begin{array}{c}-0.056 \\
(-0.077)\end{array}$ & $\begin{array}{c}0.116 \\
(0.126)\end{array}$ & $\begin{array}{c}0.039 \\
(0.031)\end{array}$ & & \\
\hline
\end{tabular}

Notes:

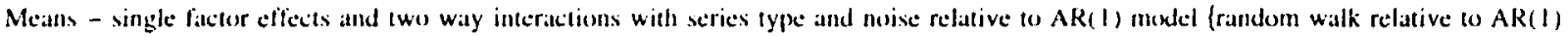
modst results in bracketst.

The lower the value the better the pertiormance relative to the AR(1) model.

Positive values indicate pertormance worse than the AR(I) model and negative values indicate perfiurnance beller than the AR( 1$)$ model.

ance was worse than the model in the stochastic drift case, much worse in the constant drift case, and worst of all in the constant with stochastic drift case. It would appear that the model wals much better in picking up the constant drift, and to a lesser extent, the stochastic drift, than the subjects. The model's ability to identify the zero drift situation was similar to the subjects as a whole. The mean response indicaltes that the subjects particularly underestimated the constant drift in the series, giving lower responses in these cases (Table 4). Subjects, however, were still overconfident relative to the model reflecting that they not only underestimated the drift but were poor at identifying it (Table 5). Hence, the model appeared, as would be expected, to perform much better than the subjects particularly where 
Tatile 4

Mean response difference - subjects

\begin{tabular}{|c|c|c|c|c|c|c|c|}
\hline & \multicolumn{4}{|c|}{ Series type/drift } & \multirow[t]{2}{*}{ All } & \multicolumn{2}{|l|}{ Noise } \\
\hline & $\begin{array}{l}1 \\
\text { Zero }\end{array}$ & $\begin{array}{l}2 \\
\text { Constant }\end{array}$ & $\begin{array}{l}3 \\
\text { Stochastic }\end{array}$ & $\begin{array}{l}4 \\
\text { Stochastic } \\
\text { and constant }\end{array}$ & & Low & High \\
\hline \multicolumn{8}{|l|}{ Expertise } \\
\hline All & 0.002 & -0.073 & 0.014 & -0.058 & 0.029 & -0.031 & -0.027 \\
\hline Novice & 0.013 & -0.064 & 0.028 & -0.048 & -0.018 & -0.019 & -0.017 \\
\hline Expert & -0.032 & -0.101 & -0.028 & -0.087 & -0.062 & -0.068 & -0.056 \\
\hline \multicolumn{8}{|l|}{ Horizon } \\
\hline 1 month & 0.048 & 0.016 & 0.034 & 0.041 & 0.035 & 0.015 & 0.055 \\
\hline 2 monith & 0.026 & -0.034 & 0.022 & -0.037 & -0.006 & -0.007 & -0.005 \\
\hline 3 month & 0.008 & -0.071 & 0.017 & -0.068 & -0.029 & -0.027 & -0.030 \\
\hline 4 month & -0.013 & -0.097 & 0.009 & -0.083 & -0.046 & -0.043 & -0.047 \\
\hline 5 month & -0.025 & -0.119 & 0.004 & -0.096 & -0.056 & -0.058 & -0.060 \\
\hline 6 motuth & -0.032 & -0.135 & 0.000 & -0.106 & -0.068 & -0.066 & $-0.07 !$ \\
\hline \multicolumn{8}{|l|}{ Voise } \\
\hline Liw & -0.039 & $-0.06,7$ & 0.0 .33 & -0.051 & -0.031 & & \\
\hline High & 0.042 & -0.080 & $-0.0(4)$ & -0.065 & -0.027 & & \\
\hline \multicolumn{8}{|c|}{ Evpertise/noise } \\
\hline Novice/low & -0.025 & -0.058 & 0.047 & -0.038 & -0.019 & & \\
\hline Expert/low & -0.079 & -0.093 & $-0.0(x) 6$ & -0.042 & -0.068 & & \\
\hline Novice/hiph & 0.051 & -0.070 & 0.010 & -0.050 & -0.017 & & \\
\hline lixpert/high & 0.016 & $-0.1(1)$ & -0.048 & -0.083 & -0.056 & & \\
\hline
\end{tabular}

Nintes:

Mcans - single factor eflects and (wo way interactions with serics lype and noise relative fo AR( $\mathrm{A}$ ) model.

Posilive values indicate a higher mean response than the AR(1) medel and negative values indicate a lower mean response than the AR( I) tmolcl.

constant drift was present in the series. Of the four factors, noise appeared the least important, giving non-significant results $\{\boldsymbol{F}(1,585)=2.72, \mathrm{~ns}\}$.

There were also important two-way interactions for the MAPSD. The interaction between expertise and series type was significant $\{F(3.585)=22.80$. $P<0.001\}$ with the main difference occurring between the performance of experts and novices on the zero and stochastic drift cases (Table 3). For series types displaying a constant drift element, experts performed better than the random walk forecaster while the novices performed worse. It was, of course, impossible for the subjects to perform better than the random walk forecaster on the zero drift type and. as the expected directional movement and probabilities for the stochastic drift type approached those of the random walk series when the forecast horizon was increased (i.e. the expected effect of the stochastic drift shock diminished over time), it was not surprising that subjects would perform worse than the random walk forecaster on this series type also. Experts performed better than the $A R(1)$ model while the novices performed considerably worse. On all series types experts gave much lower probability responses than the novices and the AR(1) model (Table 4). For the zero drift series type, in particular. the experts showed under confidence relative to the model while novices showed overconfidence (Table 5). These results suggest that experts, who are familiar with the efficient market hypothesis and understand that currencies can often move in an apparently random way, are more ready to accept situations where they could not predict the direction of change in the series than novices. The interaction between horizon and series type was also significant $\{F(15,585)=27.22, P<0.001\}$ with the best per- 
Tahle 5

Bias difference - subjects

\begin{tabular}{|c|c|c|c|c|c|c|c|}
\hline & \multicolumn{4}{|c|}{ Series type/dritt } & \multirow[t]{2}{*}{ All } & \multicolumn{2}{|l|}{ Noise } \\
\hline & $\begin{array}{l}1 \\
\text { Zero }\end{array}$ & $\begin{array}{l}2 \\
\text { Constunt }\end{array}$ & $\begin{array}{l}3 \\
\text { Siochastic }\end{array}$ & $\begin{array}{l}4 \\
\text { Stochastic } \\
\text { and constant }\end{array}$ & & Low & High \\
\hline \multicolumn{8}{|l|}{ Expertise } \\
\hline All & 0.002 & 0.021 & 0.025 & 0.083 & 0.033 & 0.039 & 0.026 \\
\hline Novice & 0.014 & 0.033 & 0.038 & 0.097 & 0.045 & 0.052 & 0.0 .38 \\
\hline Expert & -0.032 & $-0.01 t$ & -0.013 & 0.040 & -0.005 & 0.000 & -0.010 \\
\hline \multicolumn{8}{|l|}{ Horizom } \\
\hline 1 month & 0.048 & 0.080 & 0.049 & 0.116 & 0.074 & 0.068 & 0.079 \\
\hline 2 mouth & 0.026 & 0.044 & 0.035 & 0.126 & 0.058 & 0.062 & 0.053 \\
\hline 3 month & 0.008 & 0.032 & 0.023 & 0.098 & 0.041 & 0.045 & 0.0 .37 \\
\hline 4 month & -0.013 & 0.007 & 0.017 & 0.075 & 0.021 & 0.033 & 0.010 \\
\hline 5 munth & -0.025 & -0.008 & 0.013 & 0.040 & 0.0015 & 0.014 & -0.0015 \\
\hline 6 month & -0.032 & -0.029 & $0.0 \times 19$ & 0.042 & -0.003 & 0.011 & -0.016 \\
\hline \multicolumn{8}{|l|}{ Norive } \\
\hline Low & -0.0 .30 & $0.0 \times 17$ & 0.074 & 0.113 & 0.0134 & & \\
\hline High & 0.1442 & -0.013 .5 & -0.024 & 0.052 & $0.0) 26$ & & \\
\hline \multicolumn{8}{|c|}{ Inperrise/norise } \\
\hline Novice/low & -0.026 & 0.020 & $0.0 \times 6$ & 0.128 & 0.052 & & \\
\hline Expert/low & -0.074 & -0.020 & $0.11+61$ & $0.0(14)$ & $(1 .(x) 1)$ & & \\
\hline Novice//high & 0.0 .51 & 0.046 & -0.010 & 0.060 & 0.0138 & & \\
\hline Ifxpert/hight & 0.016 & $0.0(x)$ & $-0)(0)(0$, & 0.012 & $-(x) .010$ & & \\
\hline
\end{tabular}

Nincs:

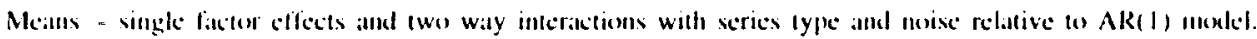

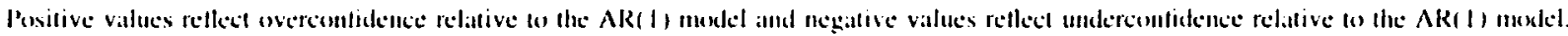

lormance occurring with acro drift and improving as the horizon increased. The subjects, in lict, performed beller than the model in the longer horizons (Table 3). Pertormante on the other three types were, however, worse than the model and much more constant over the horizon. The mean probability responses indicated the subjects gave responses similar to those of the model. In particular, even though the probability responses were slightly higher than the model in the 1-month horizon, they declined als horizons increased (Table +). While the zero and stocharstic drift responses did not show a marked diflerence from the model, this was not the caste when constant drift was present. In these citses, the responses were considerably less than the model. Overcontidence relative to the model was, however, grealtest in this combined calse but generally declined for all series types over the horizons (Table 5). It appears that the subjects' poor perlormance relative (1) the model reflected their inability correctly to identify the constant drift situations. The subjects performance lended to be worse than the model when constant drift occurred in al series, but when it was not present the subjects performance was similar to the model. The interaction between drift type and noise $w_{\text {:ls }}$ also significant $\{/(3,585)=$ $6+4.96, P<0.001\}$, indicating that the main differences occurred in series which did not contain constant dritt (Table 3). In the zero drift ciase with low noise and in the stochastic drift calse with high noise, the performance of the subjects wils better than the $A R(1)$ model. In terms of probability responses, the only marked difference occurred in the zero-drift calse with much higher probability responses being given in the high-noise (grealer than the model) compared with the low-drift case (less than the model) (Table 4 ). In this zero-drift highnoise calse, predictions were more overcontident than the model but the low-noise predictions were more under contident (Table 5). This wats reversed, how- 
ever, in the stochastic drift ease. These results suggest that the level of noise can have both positive and negative effects on judgemental extrapolation. There was also a significant interaction between horizon and noise $\{F(5.585)=21.46 . P<0.001\}$ indicating that. as the forecast horizon increased. there was a consistent improvement in performance relative to the model in the low-noise case with a fairly constant performance in the high-noise calse (Table 3). Performance was. however, worse than the model in all cases. The results for the probability responses did not indicate that this could be explained by differences in the probability responses (Table 4 ). but overcontidence tended to be higher in the lownoise case (Table 5). In fiact. the high-noise situation with horizons of 5 months or more showed under conlidence relative to the model. The poorer performance in the high-noise case at the longer horizons could be explatined by less accuralle directional prohability responses. It appears that it wats much easier for the subjects to identily the signal in the low-moise sillation in comparison with the highmoise situation.

As for the three-way interactions for the MAPSD, expertisce drift lype and moise were signilicant $\{r(3,585)=8.6, P \cdot 0.0(0)\}$. Tathle 3 shows that the experts performed better than the nevices on all four series types at both moise levels: hewever, marked differences oceurred on the gero drift series with low noise (i.e. experts had a mean value of -0.080 as compared to that of the movices of -0.024 ) and the stochatstic drift series with high moise (i.c. experts had a meinn valuc of -0.0 .56 als compatred to that of the novices of $-0.0(0) 7$ ). These results suggest that the experts were more shilled at identifying stechasslic dritt in series as well as distinguishing it from random fluctuations. Further evidence that the experts behatved differently where randemeness wats concerned is rellected in their mein probability responses over the four series types ats compared with those of novices. The novices had higher mean responses that the experts in all catses but exhibited retalive constancy across series types (i.e. (0.60). (0.60). 0.60 and 0.61 . respectively). The experts, on the other hand. exhibited lewer mean responses on the zero and stochastic drift scries (i.e. 0.55. 0.57. 0.5t and 0.57 respectively). These results suggest that while the novices viewed the four series lypes as being of roughly equal difficulty to forecust. the experts appreciated that series with random characteristics were particularly difficult to forecast. There was also a significant interaction between horizon. drift type and noise $\{F(5.585)=7.20, P<0.001\}$. This result indicated that the zero-drift case enabled better predictions relative to the model in all but the first horizon in the low-noise case (i.e. mean values for the 1 to 6 month horizon of: $0.013,-0.004$. -0.028 . $-0.055 .-0.070$ and -0.085 ) and that with stochastic drift gave better predictions than the model over all horizons in the high-noise case (i.e. mean values for the 1-6 month horizon of: -0.009 . $-0.016,-0.015,-0.025,-0.023$ and -0.029 ). This suggests that different levels of noise can hatce an influence on the identification of gero drift and stechastic drilt series with the subjects performance tending to improve relative (o the AR(1) model as the forecant horizon is increased.

\section{Conclusion}

The present investigation reveals crucial insights for the fintancial forceasting domain. Our results stgegest that experts' probabilistic currency forecatss are clearly more accurate than mon-experts forceasts. These lindings contirm Whilecotton (1999) results regarding the suprerior accuracy of tinancial analysts' probabilistic carnings forecasts under conditions of constrained information. Our lindings are also congruent with the results of previous studies in tintancial markets showing better performance of experts under representative lank conditions (Kabus, 1976: Muradoglu and Onkal. 1994; Önkal and Muradoglu. (9)9).

Current results have importint implications for linancial decision making in that they extend the voluminous rescarch demonstrating the accuracy of

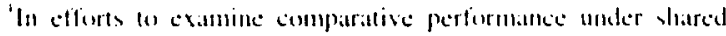

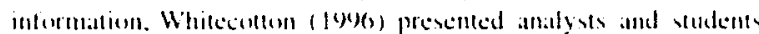
with limited timancial ratios and previous earnings data, while hisling the complany names and timc Irames. Analysts probability

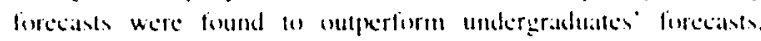

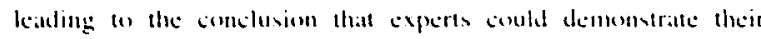
performance edse if given a constrated information set. Simblar ly. war suhjects alata were comstranted in that they were simulated

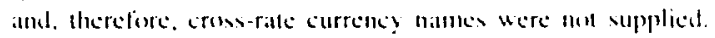


financial analysts' judgemental point forecasts. especially of earnings (Brown and Rozeff, 1978: Fried and Givoly, 1982; Armstrong. 1983: Collins et al.. 1984: Brown et al.. 1987; O'Brien. 1988; Schipper. 1991). Comparisons with time series models have suggested that the analysts' forecasting accuracy could largely be due to their use of non-time series information (see Brown (1993) for an extensive review). This suggestion has also been supported by the Affleck-Graves et al. (1990) study. which compared the earning forecasts of students (having only time series information) with those of analysts (having non-time series information as well), yielding superior accuracy for the latter group.

Following O'Connor and Lawrence (1989), we argue that a detailed investigation of time series extrapolative judgement necessirily entails eliminating non-time series information and exploring expert performance under those conditions. The current study presents such an attempt in a situation where the provision of time series information alone does not reduce ecological validity. We employ probability forecasts ats a means for consolidating the inherent uncertainties in finalncial markets not reflected by poine foreciasts. Within a currency forecasting framework. we find that experts call effectively outpertorm non-experts under conditions of equall access to time series information. One potential explanation for this finding may involve the nature of expertise in currency forecasting. In particular, the experts in this study possessed specific knowledge of the nature of currency series in addition to their general knowledge of financial forecasting. Unlike the experts who had substantive knowledge about the existence and nature of random walk processes and market efficiency, students may not have been aware of the important theoretical implicaltions of these concepts to currency forecasting, leading to poorer performance. Further research maly test this assertion by concealing the currency identitication of series and using participants with differing levels of expertise in financial forecasting.

Another explanation may relate to proposed arguments on potential hazards of experts' richer cognitive representations. As summarised by Whitecotton (1996). this view suggests that the presentation of selective information may serve to prevent the experts from using irrelevant and unproductive cues. hence enabling better accuracy. Belatedly. Yates et al. (1991) maintain that increased experience within a domain leads to more beliefs being formed about what types of information are predictive of relevant target events. False beliefs are corrected relatively easily in domains where feedback is reliable (e.g. Kaiser and Proffitt. 1984): but in some complex systems the correction of erroneous beliefs is practically impossible. Consequently, greater experience in such systems can lead to a greater reliance on weak cues (e.g. Gaeth and Shanteau. 1984; Poses et al., 1985). Secondly. Yates et al. (1991) contend that. even if additional cues are valid. better performance is not guaranteed. For instance. lens model research has demonstrated that even the addition of valid cues can be detrimental to performance: additional cues cannot only be misused. but they can reduce the individual's reliability by making the task more difficult (Dudychal and Naylor, 1966). These arguments have direct implications for designing support systems to aid forecasters in effective and efficient processing of information. Future rescarch examining forecasters" search for and use of different levels of contextual and time-series information may enhance our understanding of these important issues.

Another critical result emerging from the present study reflects the experts" ability to deal with random series. Not only is this expert ability superior to that of novices, but also it outperforms the AR(1) model. These results support the findings of Lawrence (1983): Edmundion el al. (1988) and Sanders and Ritzman ( 1992 ). The superior performance of human judgement in this calse perhaps reflects two undesirable characteristics of models in general. Firstly, models tend to underestimate uncertainty beciuse they cannot lake all of its sources into account. Secondly, models altempt to identify signals in the data even when they are non-existent. Our experts, on the other hand, familiar with the characteristics of currency data. were able to accept that such series call exhibit random movements. In the present study. the experts were fiked with a task which was, arguably. consistent with Ayton et al. (1989) criteria of being logically and methodologically appropriate. and this further supports the view that humans can recognise randomness (Baddeley, 1966; Cook. 1967; Harvey, 1988). Further research delineating the effects of feedback on such tasks would be extremely 
valuable for users of judgemental forecasts (Benson and Önkil. 1992: Bolger and Wright. 1993. 1994; Önkal and Muradoglu. 1995; Yates et al., 1996).

Another interesting result is that the experts and the AR(1) model performed similarly on the stochastic drift series. with the experts significantly outperforming the model in the high-noise case. The comparative performance of experts and the $\operatorname{AR}(1)$ model supports Yaniv and Hogarth (1993) assertion that. in dynamic (high-noise) environments. humans may better utilise some infrequently-occurring cues that are difficult to include in statistical models. Accordingly. our results could also be viewed as suggesting that the experts were also able to concentrate on recent movements of the series as well as the overall trend. Support for this explanation comes from point forecasting studies concerned with the anchoring and adjustment heuristic (Bolger and Harvey, 1993; Goodwin and Wright. 1994: Lawrence and 0 Comnor, 1995). The relevance of this heuristic in a currency forecasting context could provide a promising direction for future rescarch.

The interaction of series type and horizon is also intriguing. When the series contains no overall trend, subjects performance, relative to the model is lound 10 improve as the horizon is extended. llowever, when an overall trend is present, the subjects performance, relative to the model is similar for all horizons. Not only do these results help explatin the contradictory horizon effects discussed in the introduction but they suggest that the whole issute of the effect of forceast horizon on performance is much more complicated than was previously thought, and that it depends largely on the nature of the datta and the experience of the forecister. These issues also warrant further investigation.

\section{Acknowledgements}

This is a revised version of the paper presented at the International Symposium on Forecasting, Istanbul. Turkey. Junc, 1996 and the I9th. Mecting of the I:URO Working Group on Financial Modelling. Chania. Greece. November. 1996. The authors would like 10 thank Marcus O'Connor, Fergus Bolger and an anonymous referec for their helpful comments on an earlier version of the paper. The authors would also like to thank Alex Macaulay and William Gardiner for their advice on statistical aspects of the paper. and Nigel Harvey for his advice on series construction. The research was carried out in partial fulfilment of the requirements for a Ph.D. currently being undertaken by the tirst author.

\section{Appendix A}

\section{Ohtaining the theoretical expected direction and probability values of the series}

The expected logarithmic exchange rate changes for one step ahead or more $\{$ i.e. $E(\Delta y, \ldots)$,$\} are given$ by Eq. (A1).

$\ell\left(\Delta y_{1,+, r}\right)=\mu+\rho^{\top}\left(T_{1}-\mu\right)$

The optimal directional change for the $1-6$ months alhead forecasts the sign of $E\left(J_{y_{1}+r}\right)$ from $E$ :

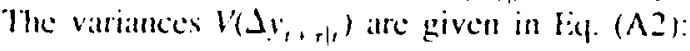

$V\left(\Delta y_{t+r}\right)=\sigma^{2}+\sigma_{r}^{2}\left|\left(1-\rho^{2 r}\right) /\left(1-\rho^{2}\right)\right|$

The combined variances over $\tau$ periods are given in [E. (A.3):

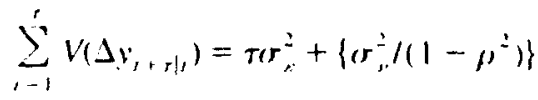

$$
\begin{aligned}
& \times\left\{\tau-\rho^{2}\left|\left(1-\rho^{2 r}\right) /\left(1-\rho^{2}\right)\right|\right\}
\end{aligned}
$$

The normally distributed values $\left(\varepsilon_{p}\right)$ for the $\tau$ step ahead forecasts are given in Eq. (At):

$$
\begin{aligned}
z_{\sigma}= & \left\{\tau \mu+\left\{\rho\left|\left(1-\rho^{r}\right) /(1-\rho)\right|\right\}\left(T_{,}-\mu\right)\right\} / \\
& \left\{\tau \sigma_{r}^{2}+\left\{\sigma^{2} /\left(1-\rho^{2}\right)\right\}\right. \\
& \left.\times\left\{\tau-\rho^{2}\left|\left(1-\rho^{2 r}\right) /\left(1-\rho^{2}\right)\right|\right\}\right\}^{\prime}=
\end{aligned}
$$

As $z_{r}$ follows a standard normal distribution probability estimates for the directional change are directly obtained. That is, taking the absolute value of $z_{r} .\left|E_{r}\right|$. the probability associated with the expected directional change was obtained from the cumulative distribution function of the standard normal distribution for the given balues of $z$ i.e. $\left.d\left(\left|\Sigma_{,}\right|\right)\right\}$. This probability has a minimum valuc of 
0.5 i.e. $(x \mid z, 1)=0.5$, when $z_{z}=0$ \} and a maximum value of unity $\left\{\right.$ i.e. $\Phi\left(\left.\right|_{-} \mid\right)=>1$. when $\left.\left|\Sigma_{r}\right|=>x\right\}$.

\section{References}

Adam. E.E.. Eher. R.J.. 1976. A comparionn of human and stutistical forecasting. AllE Transictions 8. 120-127.

Affleck-Graves, J. Davis, L.R.. Mendenhall, R.R.. 1940. Forecasts of earnings per share: powible sources of analysts superiority and bias Contemporary Accounting Revearch 6. $501-517$.

Andreassen. P.B.. 1988. Examining the price-volume relationship: the difference beween prise changes and changing prices. Organizational Bchariour and Human Decivion Precessess +1 . $3711-37 \% 9$

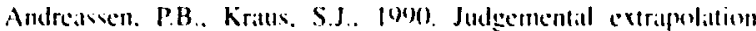
and the sillisence of change. Journal of Forecasting 9. 347-372.

Armerong. J.S. Ios3. Relative ancoraty of judgentental and extrapolative metheds in lorecasting annual carmings. Jomrail of Forciating 2. 437-447.

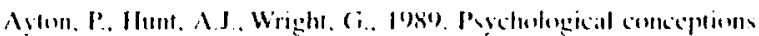

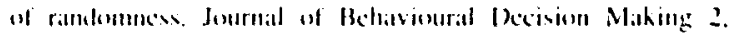
$221-238$.

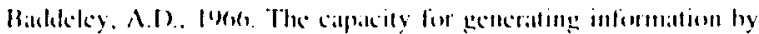

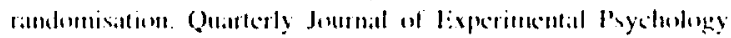
IS. 1113123

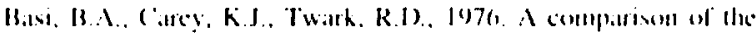

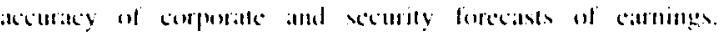
Acconuting Revicw 51, 2.44 = 25.4.

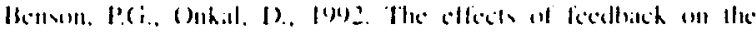

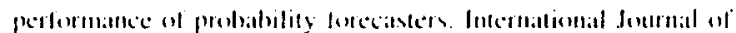
fincensing 8 , 550 573

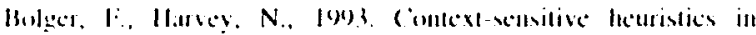

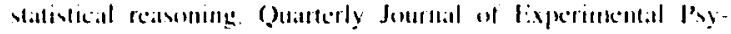
cholugy $f(1, x, 770)-811$.

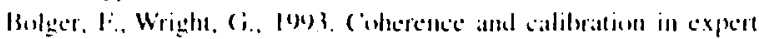

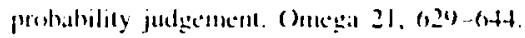

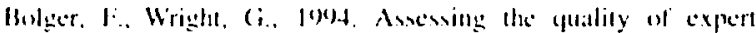

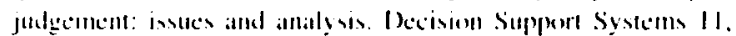
$1-24$.

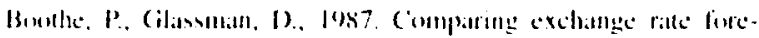

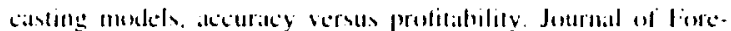
(ancing 3, $65-74$

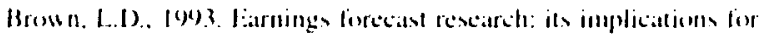
capitat markets rexcarch. International Journal of forccasting". $245-320$.

Broun, L.D). Hagermast, K.I.. (irittin, P.A. Zmijewshi, M.I:.

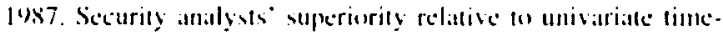

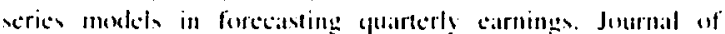
Accounting Rescarch 9. $01-\$ 7$.

Brown. 1..D.. Ro/eff. M.S. (1)78. The superiority of antalysts" fercoasts as measures of expectations: cridence from carninges. The Journal of finance $3.3,1-16$.

Collim, W... Hopuond. W. Mckeown, J.C.. 1984. The predic. tahility of interim earnings over alternative quarters. Journal of Accounting Reseatch 22, $467+474$
Conkt. A. 1967. Recognition of hids in stringes of binary digits. Perception and Moter Shill, 24. 10013-10060.

Crumbs. R.E.. Ohstfidd. M., 198t. International interest rats linkages under hexible exchange rates: a review of recent evidence. In: Bilson. J.F.O. Marston. R.C. (Eds.). Exchange Rate Theory and Practice. Chicago Press. Chicago.

Dalrymple. D.J.. 1987. Sales forecasting practices. International Journal of Forecasting 3. 379-391.

Dudycha. L.W., Naylor. J.C.. 1966. Characteristics of the human inference process in complex choice hehaviour situations. Organizational Behaviour and Human Performance 1. 110IIs.

Edmundsen. R.. Lawrenct. M.. O'Connor. M.. 19:88. The use of non-cime series information in sales forecasting: A calse study. Journil of Forecasting 7. 201-211

Eggleton. I.R.C.. 1982. Intuitive time-serics extrapolation. Journill of Accoumting Rescourch 20, $68-102$

Fricd. D. Givoly. D. 1482. Financial analysts foreciosts of carnings: a better surrogate for market expectations. Journal of Aconuting and Eonemonics $\$$, 85-107.

Gitcth. (i.J., Shomteitu. J., lest. Reducing the influcme of irrelevint information on experiented decisinn matkers. ()rganti

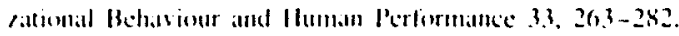

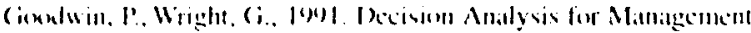
Judertment. Willey. (hichester

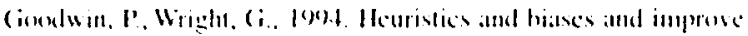

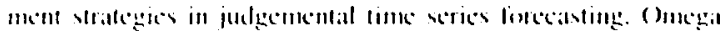
22. $553.50,8$

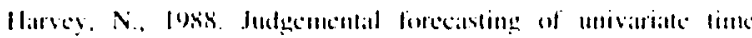

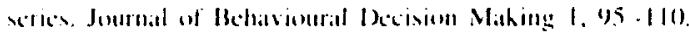

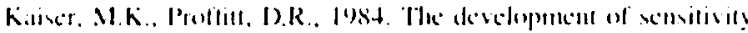

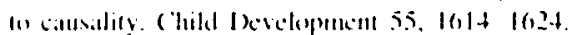

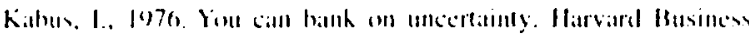
Revien st $95-105$

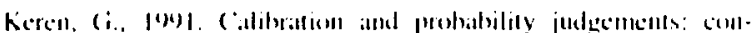

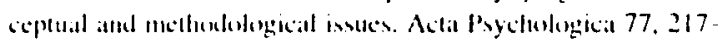
23.

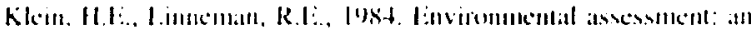
internationat study of corperatce practice. Joumal of Businew Siralegy $5 .(16)-84$.

L.amrence, M.J., IOS.3. The explesation of some practical issues in the use of quantitative forceasting. Journal of forctionting ?. $169-179$.

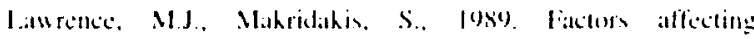

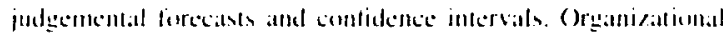

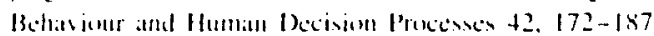

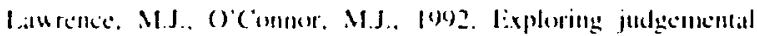

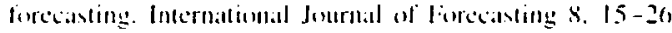

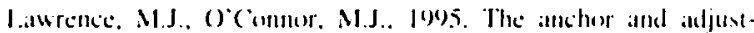

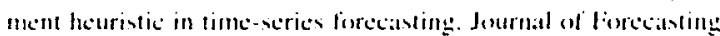
14. $4+3-451$.

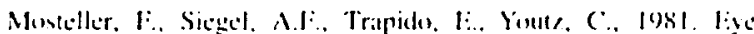
timing stratght lines. The American Statistician 35. 150-152.

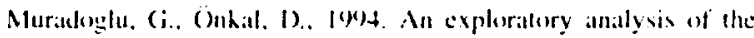

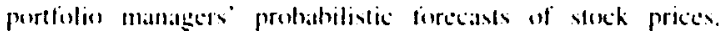
Journal of forcconving 1.3. 56.5-578.

Murphy. A.II. Winkler. R.I... 197. Subjeclive probalbility experiments in meteorology: some preliminary resulds. Bullectin of the

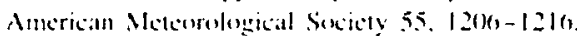


Murphy. A.H.. Winkler. R.L., 1992. Diagnostic veritication of probatility forecasts. International Joumal of Forecasting 7. $435-455$.

Murphy. J.J., 1986. Technical Analysis of Futures Markets. Prentice Hall. New York.

Netson. C.R.. Plosser. C.1.. 1982. Trends and random walks in macrecconomic time series: some evidence and implications. Journal of Monetany Economics 10. 139-162.

$0^{\circ}$ Brien. P. 1988. Analysts forecasts as earnings expectations. Journal of Accounting and Economics 10. 53-83.

OConnor. MJ.. Lawrence. MJ.. 1989. An examination of the accuracy of judgemental contidence intervals in time series forecisting. Journal of Forecasting $8.1+1-155$.

Otficer. L.H. 1482. Purchasing Power Parity and Exchange Rattes: Theory. Evidence and Relevance. Contemporary Studies in Economic and Financial Analysis. Volume 35. J.A.I.. London.

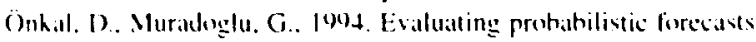
of elech prices in a developing stock market. Europeion Journal of (Operatumial Revearch $7+, 350-358$

Oukial. D.. Muradeglu, (i., 1905. Eeffects of feedtach an prob-

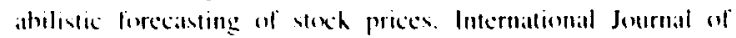
loneciating $11.307-319$.

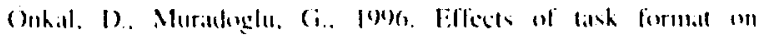

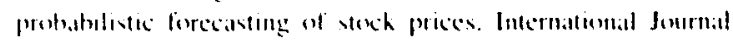

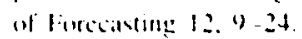

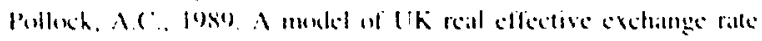

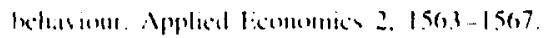

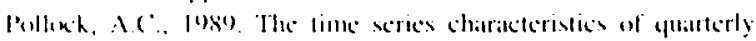

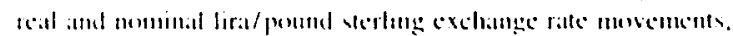

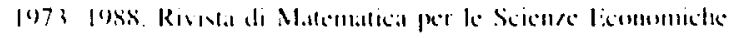

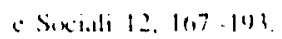

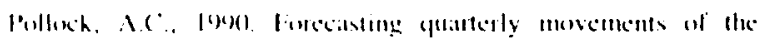

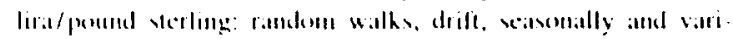

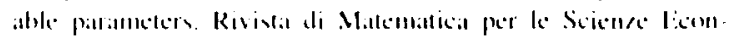
omiche se seriali 13, 23-11.

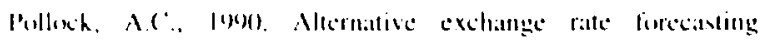

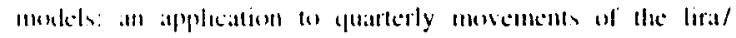

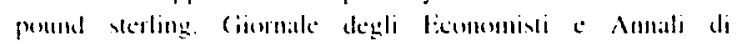
l:colemilat +4), $527-555$.

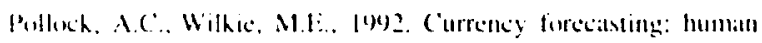

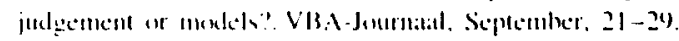

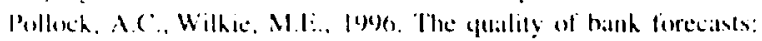

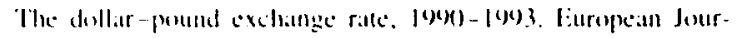

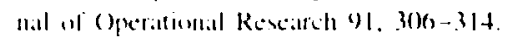

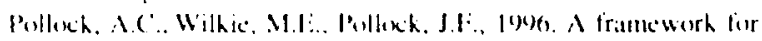

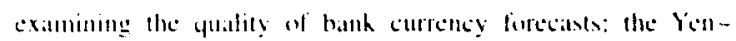

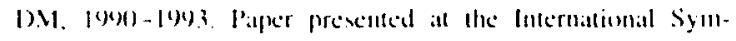

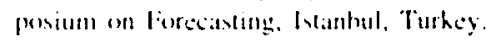

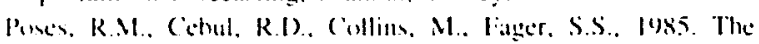
acuray of experimental physicians probahility cotimates lor

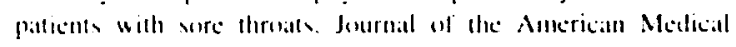
Aneciltion 254, 925-9)"

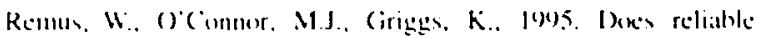
intirmatom improwe the accuratey of judgemental tereciasts? International Jesurnal of Ierecasting 11, 285-20).

Ronis, 1).1... Yates, J.f.. 1987. Components of prothahility judgement acearacy: individaal comvistency and effects of subject maller and asewnent method Organirational Behavioner and

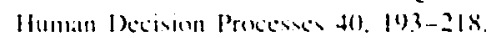

Sanders. N.R.. 1942. Accuracy of judgemental forecasts. Omega 20. 353-3nd.

Sunders, N.R.. Ritzman. L.P. 1992. The need for contextual and technical knouledge in judgentental forecasting. Journal of Behavioural Decision Making 5. 39-52.

Schipper. K.. 1941. Commentary on analysts forecasts. Account ing Horizon, $5.105-121$.

Stael von Holstein. C.A.S. 1972. Probability forecasting: An experiment related to the stock market. Organizational Behaviour and Human Performance 8. 139-158

Taykor. S.J. I980. Conjectured madels for trends in tinancial prices. tests and forecasts. Journal of the Royal Statistical Society. Seris A 1+3, 338-362.

Taylur. S.J.. 10s6. Mlodelling Financial Time Series. Wiley. Chichester

Taylor, S.J. foxy. Simulating financial prices Journal of the Operational Rescarch Socicty $40,567-560$ ).

Trersky. A.. Kahneman, [D. 1973. Avaikability: A heuristic for judging frequency and probathility. Cognitive poycholugy s. $207-232$.

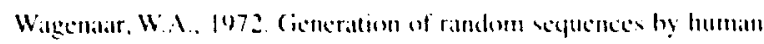
subjects: a critical survey of the liferature. Prochelengical Bulletun 77, 65-72

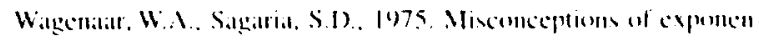

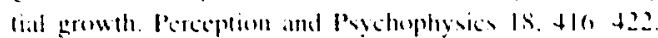

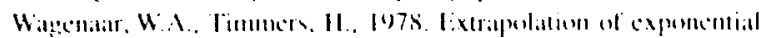

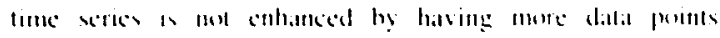

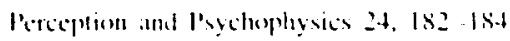

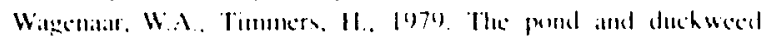

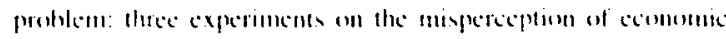

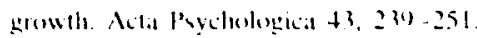

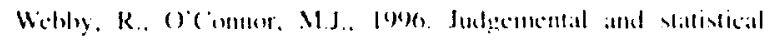

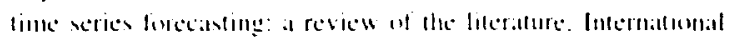
Jurmal of lintecisting 12, $191-118$.

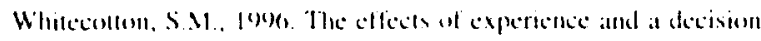

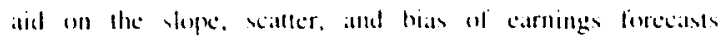

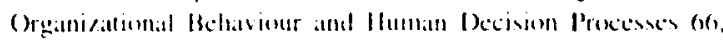
$111-121$.

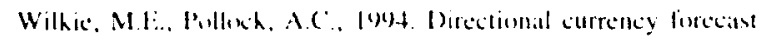
ing: an insertgattom into probahility judgement atcertacy. In

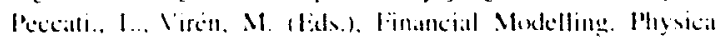
Verlatg. Herdellerts.

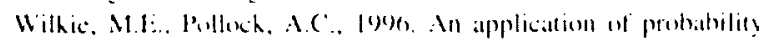

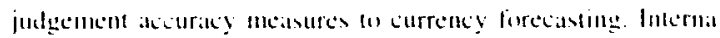

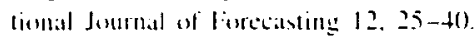

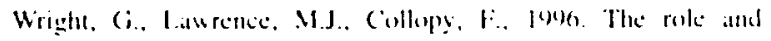

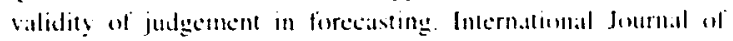
lorecinting: 12, I-8

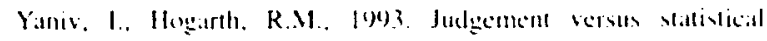

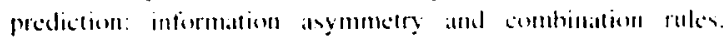

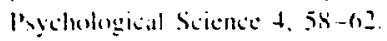

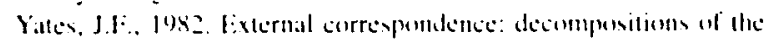

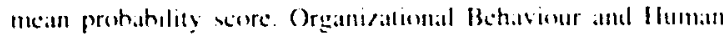
Pertombance $30.132-150$

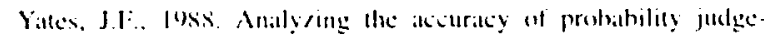
ments for multiple cenents: an extemsen of covariance de composition. Organizatmonal Bchaviour and Human Decision

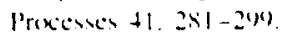


Yates, J.F.. McDaniel. L.S.. Brown. E.S., 1991. Probabilistic forecasts of stock prices and earnings: the hazards of nascent expertise. Organizational Behaviour and Human Performance 49. 60-79.

Yates. J.F., Price, P.C., Lee. J.W., Ramirez. J., 1996. Good probabilistic forecasters: the 'consumer's' perspective. International Journal of Forecasting 12. $41-56$.

Biographies: Mary E. WILKIE-THOMSON is a Lecturer in the Department of Consumer Studies. Glasgow Caledonian University. and has published articles and papers in a variety of books and journals. Her research interests focus on the role of judgement in financial forecasting and decision making.
Dilek ÖNKAL-ATAY is an Associate Professor of Decision Sciences at Bilkent University. Turkey. She received a Ph.D. in Decision Sciences from the University of Minnesota. and is doing research on decision analysis and probability forecasting. She has published in the European Joumal of Operational Research. International Forum for Information and Documentation. International Journal of Forecasting. Joumal of Behavioural Decision Making. and the Journal of Forecasting.

Andrew C. POLLOCK is a Lecturer in the Department of Mathematics. Glasgow Caledonian University. He completed a Ph.D. on exchange rates in 1988. and has subsequently published a variety of articles and papers in this area. His particular research interest is the application of analytical techniques to the forecasting of currency and. more generally, financial time series. 